\title{
sciendo
}

\section{The Proportionality Argument and the Problem of Widespread Causal Overdetermination}

\author{
Alexey Aliyev \\ HSE University \\ DOI: $10.2478 /$ disp-2020-0016 \\ BIBLID [0873-626X (2020) 59; pp.331-55]
}

\begin{abstract}
The consensus is that repeatable artworks cannot be identified with particular material individuals. A perennial temptation is to identify them with types, broadly construed. Such identification, however, faces the so-called "Creation Problem." This problem stems from the fact that, on the one hand, it seems reasonable to accept the claims that (1) repeatable artworks are types, (2) types cannot be created, and (3) repeatable artworks are created, but, on the other hand, these claims are mutually inconsistent. A possible solution to the Creation Problem is to argue that claim (2) can be rejected because (a) the only motivation for it is that a type, being abstract, cannot stand in causal relations, but (b) this motivation is ungrounded, since types can, in fact, stand in such relations. Clearly, in order for this solution to be successful, it is necessary to substantiate the possibility of types to be causally efficacious. In this essay, I examine an attempt to do this with the help of Yablo's principle of proportionality, which has been undertaken by Walters (2013) and, more recently, Juvshik (2018). Although the argument they advance may seem to provide strong support for the causal efficacy of types, I think it actually fails to do this. To explain why this is so, I first show that this argument commits us to the existence of widespread causal overdetermination involving types and then argue that this commitment is both epistemically and ontologically problematic.
\end{abstract}

\section{Keywords}

Ontology of artworks, creation problem, causal efficacy of types, principle of proportionality, causal overdetermination. 


\section{Introduction}

What basic sort of thing is a repeatable artwork - that is, an art-

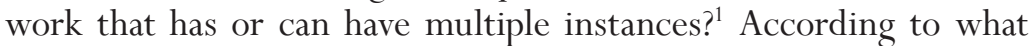
might be called "type-platonism," such an artwork is a type, broadly construed, for example: "a (pure) type" (Currie 1989, Dodd 2000, Kivy 1983), "an initiated type" (Levinson 1980), "a created type" (Walters 2013), "a norm-kind" (Wolterstorff 1980), and the like. ${ }^{2}$ While some philosophers reject type-platonism, ${ }^{3}$ an overwhelming majority believe that it provides the best possible answer to the question posed above. Despite its popularity, however, type-platonism is not unproblematic. Among the most serious problems it faces is the so-called "Creation Problem." Consider the propositions:

P1: Repeatable artworks are types.

P2: Types cannot be created.

P3: Repeatable artworks are created.

Clearly, P1, P2, and P3 cannot simultaneously be true. So, on pain of inconsistency, at least one of them must be rejected. But, obviously, a type-platonist cannot reject $\mathrm{P} 1$; the only option available to her/him is to reject P2 or P3 (or both). It seems, however, that P2 and $\mathrm{P} 3$ are true. It is widely believed among philosophers that types,

\footnotetext{
${ }^{1}$ An instance (or, to use another term, a concrete manifestation) can be characterized as whatever makes manifest to a receiver sufficiently many primary properties that must be experienced to fully appreciate the corresponding work (by "primary properties" here is meant properties through which the primary content - that is, the set of "those contentful properties that may be the ground of other contentful properties but which are not themselves grounded in contentful properties" (Davies 2010: 411) — of the work is articulated). Examples of instances are musical performances, photographic prints, (physical) sculptures, and poetry declamations. For a detailed analysis of the concept "instance," see Aliyev 2019 and Davies 2010, 2015.

${ }^{2}$ For an account of what a type is, see Wetzel 2008.

${ }^{3}$ Among them are Alward (2004), Collingwood (1958), Mag Uidhir (2013), and Sartre (2004).
} 
being abstract, are causally iner $t^{4}$ and, hence, cannot be created. ${ }^{5}$ The creatability of repeatable artworks, on the other hand, is one of the most central ideas to thought about art. ${ }^{6}$ As a result, a problem arises: Which of the propositions- P2, P3, or both — and on what grounds, should a type-platonist reject?

One possible solution to this problem is to argue that it is $\mathrm{P} 2$ that should be rejected, since:

(a) the only motivation in favor of $\mathrm{P} 2$ is that a type, being abstract, cannot stand in causal relations, but

(b) this motivation is ungrounded, since types can, in fact, stand in such relations.

Clearly, in order for this solution to be successful, it is necessary to substantiate claim (b). While there have been a number of attempts to do this, in what follows, I would like to examine the attempt that has been undertaken by Walters (2013) and, more recently, Juvshik (2018). They argue, independently of each other, that (b) could plausibly be substantiated using Yablo (1992, 1997)'s principle of proportionality - the principle that, in theory, makes it possible to establish whether something is the cause of a given effect. Prima facie, Walters (2013)'s and Juvshik (2018)'s argument — which might be called "the Proportionality Argument"-provides strong support for (b). On closer inspection, however, it fails to do this. My purpose in this es-

${ }^{4}$ As Mag Uidhir (2013) points out, "should any general characterization of abstracta have a plausible claim to being standardly held, it clearly must be that abstracta are non-causal (especially given the standard, broad characterization of concreta as causally efficacious material inhabitants of space-time).” (10)

${ }^{5}$ Although the view that creation requires an object being created to have the capacity to stand in causal relations is nearly universally accepted, it has been challenged by Deutsch (1991). His argument, however, has been heavily criticized (for some powerful objections to it, see, e.g., Predelli 2001).

${ }^{6}$ As Levinson (1980) puts it: "The whole tradition of art assumes art is creative in the strict sense, that it is a godlike activity in which the artist brings into being what did not exist beforehand much as a demiurge forms a world out of inchoate matter. The notion that artists truly add to the world, in company with cake-bakers, house-builders, law-makers, and theory-constructers, is surely a deep-rooted idea that merits preservation if at all possible." (66-7) 
say is to explain why this is so.

The rest of the essay is structured as follows. I start by making some preliminary conceptual clarifications (Section 2). Then I turn to an examination of the Proportionality Argument, arguing, contra Walters (2013) and Juvshik (2018), that if this argument is sound, then we must accept the existence of widespread causal overdetermination, or, in other words, that there are a multitude of situations where there are two or more distinct causes such that each of them has independently brought into existence one and the same effect (Section 3). Next, drawing upon Sider (2003), I explain why the foregoing consequence is problematic and show that none of the potential responses available to a proponent of the Proportionality Argument stands up completely to criticism (Sections 4 and 5).

Before proceeding, it is worth stressing that in this essay, I do not intend to show that types cannot stand in causal relations. Nor do I intend to refute type-platonism (in fact, the truth of this view can be assumed throughout the paper). My goal is rather modest: It amounts to showing, contra Walters (2013) and Juvshik (2018), that claim (b) cannot be substantiated by means of the Proportionality Argument.

\section{The principle of proportionality}

Since the Proportionality Argument is based on Yablo $(1992,1997)$ 's principle of proportionality, let us begin by explicating this principle. Yablo $(1992,1997)$ introduces it as a means to establish which of the potential candidates for the role of the cause of a given effect is the most appropriate for this role. ${ }^{7}$ The core idea behind the principle is rather intuitive: Something can be the cause of an effect to the extent that it is proportional to this effect, where "proportionality" is defined as follows:

$C$ is proportional to $E$ iff it is both required by and enough for $E .^{8}$

To illustrate, suppose Joan has received a speeding ticket near a po-

7 That being said, Yablo (1992, 1997) does not intend the principle of proportionality to be a sufficient condition for being the cause; in his view, this principle can only serve as a constraint on causality.

${ }^{8}$ See Yablo 1997: 267. 
lice radar unit. What caused her to be ticketed? One potential answer is that it was her driving through the radar. But this answer is unsatisfactory, as her driving through the radar does not satisfy the condition of proportionality: It is not enough for the effect, since she could have driven through the radar without having been ticketed. Another potential answer is that what caused Joan to be ticketed is her speeding through the radar sober. But, again, this answer cannot be accepted, since her speeding through the radar sober does not meet the condition of proportionality: It is not required by the effect because to be ticketed, she did not have to speed through the radar sober. What is then the right answer? Joan's speeding through the radar was enough for her to be ticketed. Furthermore, Joan would not have been ticketed if she had not speeded through the radar. Thus, her speeding through the radar is proportional to the effect and, hence, can serve as the cause of her having been ticketed. ${ }^{9}$

Although the foregoing account of Yablo (1992, 1997)'s definition of "proportionality" is rather intuitive, it is necessary, for our subsequent analysis, to further clarify certain notions it employs, in particular the notions of "being required by" and "enough for." According to Yablo $(1992,1997)$ :

$C$ is enough for $E$ iff it screens off all of its determinates. ${ }^{10}$

$C$ is required by $E$ iff none of its determinables screens it off. ${ }^{11}$

Here, by "determinate" and "determinable," Yablo (1992, 1997) means the following:

$Y$ is a determinate of $X$ iff " $Y$ necessitates $X$ (not because it has a metaphysically infallible way of bringing $X$ about but) because $X$ is immanent in or included in Y" (Yablo 1997: 275); correspondingly, $X$ is a determiable of $Y$ iff $Y$ is $X$ 's determinate. ${ }^{12}$

${ }^{9}$ See Yablo 1997: 258-9.

${ }^{10}$ See Yablo 1997: 267.

${ }^{11}$ See Yablo 1997: 267.

${ }^{12}$ Although the notion of "necessitation" used here is somewhat vague, it can be made more precise by pointing out that according to Yablo (1992), X necessitates $Y$ (in the relevant sense) only if the following conditions are satisfied: 
To illustrate, consider some particular shapes, such as oval, square, and rectangular; they necessitate the determinable shape and, hence, are determinates of this determinable. Scarlet, crimson, and other shades of redness are determinates of the determinable redness, for they necessitate this determinable. For similar reasons, redness is a determinate of the determinable color, stabbing is a determinate of the determinable using a knife, and driving through a radar is a determinate of the determinable driving.

As regards the notion of "screening off" used in the definitions of "being required by" and “enough for," Yablo (1992, 1997)'s definition of this notion is as follows:

$C 1$ screens $C 2$ off from $E$ iff, had $C 1$ occurred without $C 2, E$ would still have occurred. ${ }^{13}$

Thus, imagine that a pigeon conditioned to peck at red to the exclusion of other colors pecks at a triangle that has a particular shade of red: scarlet. ${ }^{14}$ In this case, being a red triangle screens off being a scarlet triangle (a determinate of being a red triangle), as the pigeon would have pecked the red triangle even if the latter had not been scarlet; on the other hand, being a triangle does not screen off being a red triangle (a determinate of being a triangle), since if the triangle had not been red, the pigeon would not have pecked at it. ${ }^{15}$ Or consider again the speeding example: Joan's speeding through the radar screens off her speeding through the radar sober (a determinate of speeding through the radar), since if she had been speeding through the radar drunk, she would have also been ticketed; on the other hand, her driving through the radar does not screen off her speeding through the radar (a determinate of driving through the radar) because if she had not been speeding through the radar, she would not have been ticketed.

(1) necessarily, if $X$ exists, then $Y$ exists and is coincident with $X$ and (2) possibly, $Y$ exists and $X$ does not exist (see Yablo 1992: 265).

\footnotetext{
${ }^{13}$ See Yablo 1997: 266.

${ }^{14}$ See Yablo 1992: 257.

${ }^{15}$ It is assumed that the pigeon pecks only at red objects.
} 


\section{The Proportionality Argument}

Now that preliminary conceptual clarifications have been made, let us turn to the Proportionality Argument. The formulation of this argument comes in to versions: Walters (2013)'s and Juvshik (2018)'s. Let us focus on the former version, as it is considerably more detailed than the latter one. Walters (2013) begins by examining the following propositions:

P4: John's reading ${ }^{16}$ an Easton Ellis novel caused him to buy copies of all of Easton Ellis's other works. ${ }^{17}$

P5: John's reading that copy/a copy of American Psycho caused him to buy copies of all of Easton Ellis's other works. ${ }^{18}$

According to Walters (2013), neither P4 nor P5 provides a satisfactory description of what caused John to buy copies of all of Easton Ellis's other works. If John had read an Easton Ellis novel other than American Psycho (hereafter: "AP”), he might not have bought copies of all of Easton Ellis's other works. So John's reading an Easton Ellis novel does not screen off one of its determinates (namely, his reading a particular Easton Ellis work- $A P$ ) and, therefore, is not enough for the effect. On the other hand, John's reading that copy/a copy of $A P$ is not required to secure the effect. Had John read "the first three chapters of one copy and the remainder of another... the effect would still have occurred" (470). Furthermore:

it seems that if John reads some copy of American Psycho, there is some copy of American Psycho that John reads. But John would have gone book shopping if he'd read [all the chapters of] American Psycho without having read one of the actual copies... (470)

So one of the determinables of John's reading that copy/a copy of

${ }^{16}$ In this essay, reading is understood as the process of grasping, to a satisfactory extent, the semantic content of a text - through either looking at this text (when it is printed on something or displayed on the screen of an e-reader or some other electronic device) or listening to it (when it is presented in the form of a recording, such as an audiobook).

${ }^{17}$ See Walters 2013: 470.

${ }^{18}$ See Walter 2013: 470. 
$A P$ - namely, reading all the chapters of $A P$ - screens off this reading.

Thus, neither John's reading an Easton Ellis novel nor his reading that copy/a copy of $A P$ is proportional to his buying copies of all of Easton Ellis's other works and, hence, can be regarded as the cause of this buying. P4 and P5, therefore, fail to provide a satisfactory causal account. According to Walters (2013), what provides such an account is the proposition:

P6: John's reading American Psycho caused him to buy copies of all of Easton Ellis's other works. ${ }^{19}$

There is no determinate that is not screened off by John's reading AP, and so this reading is enough for the effect. Furthermore, this reading is required by the effect, since no determinable screens it off. As a result, John's reading $A P$ is proportional to the effect and so satisfies the condition of the principle of proportionality. In light of this, this reading seems a satisfactory candidate for the role of the cause of his buying all of Easton Ellis's other works. But if this is so, then, since $A P$ is a type, it is reasonable to conclude that at least some types can stand in causal relations.

Before proceeding further, it is worth underlining that the logic behind inferring that John's reading $A P$ is the cause is abductive. The principle of proportionality, taken on its own, can only be used to discover what entities that are already known to be capable of being causally efficacious play the role of the cause; it cannot, by itself, be used to establish what entities are causally efficacious. ${ }^{20}$ So the thesis that John's reading AP is the cause is not (and cannot be) deduced solely from this principle. Rather, this thesis is derived with the help of an additional premise - that (a) John's buying copies of all of Easton Ellis's other works must have a cause and (b) John's reading $A P$ is a plausible, and perhaps the only, candidate for the role of this

\footnotetext{
${ }^{19}$ See Walters 2013: 470-1.
}

${ }^{20}$ This follows from the fact that, as mentioned in Footnote 7, according to Yablo $(1992,1997)$, the principle of proportionality provides a constraint on causality - " $X$ does not cause $Y$ unless it is proportional to it" (Yablo 1997: 257) -, not a sufficient condition for it. 
cause. $^{21}$

Does the Proportionality Argument provide a strong reason to believe in the causal efficacy of types? Both Walters (2013) and Juvshik (2018) seem to assume that the type-involving event that serves as the cause of the corresponding effect is the only such cause. If this assumption is true, then the Proportionality Argument is unproblematic — or so it seems. But, as has already been pointed out in the Introduction, my contention is that this assumption is misguided, since endorsing the principle of proportionality leads to causal overdetermination. Consider the following proposition:

P7: John's reading a text-token of American Psycho caused him to buy copies of all of Easton Ellis's other works.

By "text-token" here is meant a concrete text written or printed on something (say, paper, papyrus, or parchment), displayed on the screen of some device (such as a computer or an e-reader), or sounded out (say, by a reader). A text-token thus understood is not the same as a copy. For example, half of one copy and the other half of another copy is not a copy (or so Walters (2013) assumes); yet half of one text-token and the other half of another text-token is, by definition, a text-token. Taking this into account, let us address the following question: Does P7 provide a satisfactory description of what caused John to buy copies of all of Easton Ellis's other works?

Prima facie, John's reading a text-token of $A P$ is enough for his buying copies of all of Easton Ellis's other works. One could object that

${ }^{21}$ Juvshik (2018)'s formulation of the Proportionality Argument is similar to Walters (2013)'s. Juvshik (2018) considers a scenario where "someone may cry from hearing any token of Requiem" (819). In this case, it can be argued, according to Juvshik (2018), that the cause of this crying is hearing Requiem itself, not one of its tokens. Juvshik (2018) does not elaborate on what the exact constituents of the argument are, but, presumably, they are analogous to the ones given by Walters (2013). Hearing Requiem is enough for the effect, since it screens off all of its determinates. Furthermore, it is required by the effect because there is no determinable that screens it off. As a result, hearing Requiem is proportional to the effect. So, assuming that (a) crying from hearing a token of Requiem must have a cause and (b) hearing Requiem is a plausible, and perhaps the only, candidate for the role of this cause, it is reasonable to conclude that this hearing can play the role of the cause. Consequently, since Requiem is a type, some types are capable of standing in causal relations. 
it is not enough for this because John's reading a text-token of $A P$ does not screen off one of its determinates, namely his reading $A P$. But this objection fails, as it is based on a false assumption - that John's reading $A P$ is a determinate of his reading a text-token of $A P$. According to Yablo $(1992,1997)$ 's account of the determinate-determinable relation discussed above, ${ }^{22} X$ determines $Y$ only if (1) necessarily, if $X$ exists, then $Y$ exists and is coincident with $X$ and (2) possibly, $Y$ exists and $X$ does not exist. So John's reading $A P$ can be a determinate of his reading a text-token of $A P$ only if in the given case, it is possible to read a text-token of $A P$ without reading $A P$. But this is impossible: Whenever one reads a text-token of $A P$, one reads $A P$.

Another potential objection is as follows. John's reading a texttoken of $A P$ can be enough for his buying copies of all of Easton Ellis's other works only if this reading is a determinate of this buying. But, in fact, it is not such a determinate. Suppose, for instance, that John reads a text-token of $A P$ very slowly (say, just one word a year) - so that when he actually finishes reading, he cannot remember the semantic content of what he has read. In this case, it is reasonable to hold that John may not buy copies of all of Easton Ellis's other works. So John's reading a text-token of $A P$ does not necessitate his buying copies of all of Easton Ellis's other works and, hence, cannot be a determinate of this buying. ${ }^{23}$

Like the previous objection, however, this objection fails. It assumes that it is possible to read a text-token without having a sufficient understanding of what has been read. But this assumption is false, as it is based on an incorrect treatment of what is meant by reading. As pointed out in Footnote 16, the concept "read" - as it is used in this essay-implies grasping, to a satisfactory extent, the sense of what has been read. So one cannot be said to have read something if $\mathrm{s} /$ he does not possess a sufficient understanding of what $\mathrm{s} /$ he has read.

Let us now turn to the question of whether John's reading a text-token of $A P$ is required by his buying copies of all of Easton

${ }^{22}$ See Section 2 (especially, Footnote 12).

${ }^{23}$ Thanks to an anonymous referee for pointing out this potential way to object to the thesis that John's reading a text-token of $A P$ is enough for his buying copies of all of Easton Ellis's other works. 
Ellis's other works. Following the logic of the explanation given by Walters (2013) in the case of P5, two reasons in favor of answering this question in the negative could be given. First: John would have bought copies of all of Easton Ellis's other works even if he had not read a text-token of $A P$ (say, if he had read the first three chapters of one text-token and the remainder of another), and so one of the determinables of John's reading this text-token - his reading the first three chapters of one text-token and the remainder of another-screens it off. Second: John would have bought copies of all of Easton Ellis's other works even if he had not read any of the actual text-tokens of $A P$ (provided that he had read $A P$ ); as a result, there is a determinable - namely, John's reading a possible text-token of $A P$ - that screens off John's reading a text-token of $A P$.

Is either of the foregoing reasons persuasive? The first reason assumes that John's reading the first three chapters of one text-token of $A P$ and the remainder of another is a determinable of his reading a text-token of $A P$. This assumption is true only if John's reading a text-token of $A P$ is a determinate of his reading the first three chapters of one text-token of $A P$ and the remainder of another. However, it is not such a determinate. The sum of the concrete text of the first three chapters of one text-token of $A P$ and the concrete text of the remainder of another text-token of $A P$ is a particular concrete text that instantiates the text of $A P$. Meanwhile, a text-token of a literary work is, by definition, any concrete text that instantiates the text of this work. So the sum of the concrete text of the first three chapters of one text-token of $A P$ and the concrete text of the remainder of another text-token of $A P$ is a text-token of $A P$. Given this, it is impossible for someone to read the first three chapters of one text-token of $A P$ and the remainder of another text-token of $A P$ without reading a text-token of AP. But according to Yablo (1992, 1997)'s account of the determinate-determinable relation, John's reading a text-token of $A P$ can be a determinate of his reading the first three chapters of one text-token of $A P$ and the remainder of another only if it is possible to read the first three chapters of one text-token of $A P$ and the remainder of another text-token of $A P$ without reading a text-token of $A P$. As a result, John's reading a text-token of $A P$ is not a determinate of his reading the first three chapters of one text-token of $A P$ and the remainder of another. Correspondingly, the latter reading is not 
a determinable of the former one.

Thus, the first of the reasons being discussed is based on a false assumption. Consider now the second reason. It assumes that John's reading a text-token of $A P$ is a determinate of his reading a possible text-token of $A P$. Is this assumption true? The answer is "Yes" only if P7 logically entails that John read one of the actual text-tokens of AP. However, P7 does not logically entail this. According to P7, John read a text-token of $A P$ simpliciter, not necessarily an actual texttoken of AP. Moreover, according to Yablo (1992, 1997)'s account of the determinate-determinable relation, in order for John's reading a text-token of $A P$ to be a determinate of his reading a possible text-token of $A P$, one must be able to read a possible text-token of $A P$ without reading a text-token of $A P$. But this is impossible. First of all, the expression "text-token" covers not only actual but also possible text-tokens, and so necessarily, whenever one reads a text-token, one reads a possible text-token. Furthermore, it is unclear how one could read a (merely) possible text-token at all. Given what has been said, John's reading a text-token of $A P$ is not a determinate of his reading a possible text-token of $A P$. As a result, like the first reason, the second one also involves a false assumption.

In addition to the mentioned reasons, it could also be argued that John's reading a text-token of $A P$ is not required for his buying copies of all of Easton Ellis's other works because there is a determinable that screens off this reading — namely, John's reading AP. ${ }^{24}$ But this reason fails, for it falsely assumes that John's reading $A P$ is a determinable of his reading a text-token of AP. According to Yablo (1992, 1997)'s account of the determinate-determinable relation, in order for John's reading a text-token of $A P$ to be a determinate

\footnotetext{
${ }^{24}$ It could be suggested that there is another potential candidate for the role of a determinable that screens off John's reading a text-token of $A P$ - his grasping the semantic content of $A P$ through listening to a corresponding audiobook (where the latter is understood as a type, not a concretum). But this suggestion misconstrues the sense of the concept "read." As pointed out in Footnote 16, grasping the semantic content of a text through listening to its audiobook is a kind of reading. So John's grasping the semantic content of $A P$ through listening to a corresponding audiobook is equivalent to his reading $A P$ and, hence, contrary to what is implied by the suggestion being discussed, cannot be an alternative to this reading.
} 
of his reading $A P$, it must be possible to read $A P$ without reading a text-token of $A P$. But this is impossible: To read $A P$, one must read a text-token of it. ${ }^{25}$ Thus, since John's reading a text-token of $A P$ is not a determinate of his reading $A P$, his reading $A P$ is not a determinable of his reading a text-token of $A$.

In light of what has been said, it can be concluded that John's reading a text-token of $A P$ is proportional to his buying copies of all of Easton Ellis's other works. If this conclusion is true, then, following the logic of the Proportionality Argument, we can argue as follows: We can assume that (a) John's buying copies of all of Easton Ellis's other works must have a cause and (b) John's reading a text-token of $A P$ is a plausible candidate for the role of this cause - and then, with the help of these assumptions as well as the fact that John's reading a text-token of $A P$ is proportional to his buying copies of all of Easton Ellis's other works, derive that this reading is the cause of this buying. ${ }^{26}$ But now we face causal overdetermination: John's buying is simultaneously and independently caused by two distinct causes - his

${ }^{25}$ One could object that reading AP does not require reading a text-token of it because it can be read by listening to a "sounding" of it (i.e., a sequence of sounds that results from reading it aloud). But this objection is based on a false assumption - that listening to a "sounding" of a literary work is not a kind of reading a text-token of this work. In fact, according to the definition of "texttoken" provided earlier in this section, a "sounding" of a literary work is a kind of text-token of this work; at the same time, as noted in Footnote 16, "reading" in this essay is understood in a broad sense- the sense according to which a literary work can be read through listening. So, contrary to what the objection being discussed assumes, one way to read a text-token of a literary work is to listen to a "sounding" of it.

${ }^{26}$ Can it really be assumed that John's reading a text-token of $A P$ can serve as a plausible candidate for the role of the cause of his buying copies of all of Easton Ellis's other works? There seems no good reason to think otherwise. As has been shown, John's reading a text-token of $A P$ satisfies the conditions of the principle of proportionality. Furthermore, from an ontological viewpoint, the possibility of this reading to stand in causal relations is uncontroversial, as both the process (the reading) and the object of this process (a particular text-token) are concreta and, hence, entities whose causal efficacy is nearly universally accepted. Note also that a proponent of the Proportionality Argument must endorse a considerably more questionable view - that at least some abstracta are causally efficacious. 
reading $A P$ and his reading a text-token of $A P .{ }^{27}$ Analogously, it can be shown that causal overdetermination is present in other similar cases (including the case discussed by Juvshik (2018)). Thus, the Proportionality Argument requires us to endorse the view that there is causal overdetermination in what might be called "type-involving" cases. Moreover, since there are actually many (and, in principle, infinitely many) such cases, this argument commits us to an even stronger view - that there is widespread causal overdetermination.

It could be objected that John's reading $A P$ and his reading a texttoken of $A P$ are, in fact, the same (and, hence, that in the case being discussed, there is just one cause). But this objection does not stand up to criticism. First of all, it seems to go against an assumption shared by both an opponent of the Proportionality Argument and its proponent - that a text-type and a text-token are essentially different entities. Furthermore, the non-identity of John's reading AP and his reading a text-token of $A P$ is entailed by Yablo $(1992,1997)$ 's conception of events. On this conception, two events are identical only if they have the same essence, where the latter is the set of cumulative properties (i.e., "properties such that any particular such property's modal status - essential or accidental — is without undue prejudice to the modal status of the others" (Yablo 1992: 261-2)) that are possessed essentially. ${ }^{28}$ Consider now the set of cumulative properties possessed essentially by John's reading AP. Presumably, it involves the property of interacting directly with an abstractum. Yet this property is not contained in the set of cumulative properties that John's reading a text-token of $A P$ possesses essentially. So the essences of John's reading $A P$ and his reading a text-token of $A P$ are not identical and, as a result, the corresponding events are not identical either.

\footnotetext{
${ }^{27}$ Note that it cannot be argued here that there is another option - that although John's reading a text-token of $A P$ and his reading $A P$ are distinct entities, his buying has only one cause- because that would be possible only if either reading were a determinate of the other (which is not the case, as has been demonstrated above).

${ }^{28}$ See Yablo 1992: 260-5.
} 


\section{The problem of widespread causal overdetermination}

Our analysis has shown that the Proportionality Argument commits us to widespread causal overdetermination. A natural response to this, on the part of a type-platonist, is to ask why this commitment is problematic. Indeed, why can't an event have two (or perhaps even more) independent causes? Consider, for instance, the following possibility: Two asteroids simultaneously hit Earth, as a result of which all humans die. Which of the asteroids is causally responsible for this? Assuming that the effect would have taken place even if just one of the asteroids had hit Earth, it can be said that hitting Earth by asteroid one and hitting Earth by asteroid two are both sufficient causes for killing all humans_ — and so this killing is causally overdetermined.

Perhaps, in light of what has been said, it can be argued that causal overdetermination can, in principle, be justified. Note, however, that the foregoing scenario describes an extremely rare situation: The probability of two asteroids having sufficient destructive power and hitting Earth simultaneously is close to zero. So this scenario can only be used to substantiate the existence of causal overdetermination per se, not widespread causal overdetermination. Meanwhile, it is widespread causal overdetermination that needs to be justified in the case of the Proportionality Argument.

A proponent of this argument should, therefore, ask: What is wrong with widespread causal overdetermination? In answering this question, it is instructive to consider Sider (2003)'s analysis of potential objections facing such overdetermination. According to this analysis, the most serious, and the only viable, of these objections is what Sider (2003) terms "the epistemic objection." 29 This objec-

29 Sider (2003) also considers and dismisses two other objections: the "metaphysical" objection and the "coincidence" one. The metaphysical objection is that causal "overdetermination is metaphysically incoherent" (721) because if causation is understood as a kind of fluid that is just enough to produce the effect, then there can exist no more than one (actual) cause (for when one of the potential causes acts to produce the effect, then "that fluid is used up, and no other potential cause can act” (ibid.)). But, as Sider (2003) points out, this objection can hardly be considered persuasive, as it is based on a highly controversial view - that causation is a kind of fluid that can be used up. According to the coincidence objection, if causal overdetermination were widespread, we would 
tion is based on the principle of parsimony (Ockham's Razor): If a theory, $A$, is more parsimonious than some other theory, $B$, then it is, ceteris paribus, rational to prefer $A$ to $B$. In the case being discussed, "parsimony" is understood in the epistemic sense, where the latter can be defined in terms of explanatory simplicity: A theory, $A$, is, ceteris paribus, more epistemically parsimonious than some other theory, $B$, if the explanation provided by $A$ is less complex than the explanation provided by $B$. The epistemic objection states that theories that presuppose widespread causal overdetermination are, ceteris paribus, less simple in the explanatory respect than theories that do not presuppose such overdetermination. The reason for this is that the former theories must explain the occurrence of a considerable number of events by referring to multiple simultaneous sufficient causes, whereas the latter theories can explain the occurrence of these events by referring to single sufficient causes. As a result, the former theories are, ceteris paribus, less epistemically parsimonious than the latter theories and so, according to the principle of (epistemic) parsimony, are inferior to them. Given this, since any theory involving the Proportionality Argument entails (at least, in type-involving cases) widespread causal overdetermination, any such theory is, ceteris paribus, inferior to any theory that enables us to avoid being committed to such overdetermination. ${ }^{30}$

In addition to the epistemic objection, theories that commit us to the existence of widespread causal overdetermination face a similar

have to acknowledge that there is "a massive, unexplained correlation between the multiple causes" (722); for example, we would have to agree that each time there is some effect from reading a novel, the two causes - reading a text-token of this novel and reading the novel itself-occur simultaneously by coincidence, and there is no explanation why this happens. The problem with this objection, according to Sider (2003), is that the correlation mentioned above does not have to happen by coincidence; there could be certain necessary truths that govern it. Thus, in the foregoing example, reading a text-token of a novel necessarily presupposes reading this novel, and vice versa; so these causes take place necessarily, not by coincidence.

${ }^{30}$ Note that we can be committed to causal overdetermination in some rare cases (e.g., the asteroid case) without being committed to widespread causal overdetermination. 
objection - the ontological one. ${ }^{31}$ This objection is based on the ontological version of the principle of parsimony: If a theory, $A$, is more ontologically parsimonious than some other theory, $B$, then it is, ceteris paribus, rational to prefer $A$ to $B$. The notion of "being more ontologically parsimonious" employed here can be understood using Quine's notion of ontological commitment: A theory, $A$, is, ceteris paribus, more ontologically parsimonious than some other theory, $B$, if $B$ is ontologically committed to some kind of entity, whereas $A$ is not committed to it. The ontological objection states that theories that presuppose widespread causal overdetermination require us to postulate more kinds of entities than the latter theories; specifically, the former theories commit us to a new kind of state of affairs - the presence of a multitude of two or more independent and simultaneous causes, whereas the latter theories do not. As a result, the former theories are, ceteris paribus, less ontologically parsimonious than the latter theories and, hence, according to the principle of (ontological) parsimony, are inferior to them. Given this, since any theory involving the Proportionality Argument entails (at least, in type-involving cases) widespread causal overdetermination, any such theory is, ceteris paribus, inferior to any theory that enables us to avoid being committed to such causal overdetermination.

A proponent of the Proportionality Argument could respond to the epistemic and ontological objections by questioning the truth of the principle of parsimony. This response, however, does not seem persuasive. The principle of parsimony enjoys near consensus: It is endorsed, in one version or another, by a considerable number of philosophers and scientists, including Aristotle, Aquinas, Kant, Galileo, Newton, Lavoisier, and Einstein. ${ }^{32,33}$ The nearly universal

${ }^{31}$ This objection is not discussed by Sider (2003).

${ }^{32}$ See Baker 2016.

${ }^{33}$ The endorsement of the principle of parsimony is not universal, however. Thus, Leibniz rejects it in favor of what is known as "the principle of plenitude"the principle according to which we should prefer theories that postulate the actual existence of all possible entities to theories that do not do this. However, Leibniz's position is based on a highly controversial assumption - that the world we live in is the best of all possible worlds with the greatest number of possible entities. Furthermore, endorsing the principle of plenitude commits us to a rather 
acceptance of the principle of parsimony is not surprising, given that this principle (a) seems to be an essential part of rationality and (b) has received considerable theoretical support. ${ }^{34}$ Surely, what has been said does not guarantee that this principle cannot be misguided. But if a proponent of the Proportionality Argument rejects it, then, given the prima facie validity of this principle, s/he must provide a satisfactory explanation of why this rejection is justified. Until s/ he does this - and it is far from obvious that s/he can plausibly do this - the response being discussed fails to defuse the epistemic and ontological objections.

A seemingly more promising response available to a proponent of the Proportionality Argument is to argue that the epistemic and ontological objections appeal to the ceteris paribus case and, hence, are compatible with the idea that widespread causal overdetermination in type-involving cases is theoretically tolerable, provided that it is shown that such overdetermination is justified. But can this, in fact, be shown?

One potential way to show this is to argue that widespread causal overdetermination logically follows from the principle of proportionality and the assumption that types exist. But this justification is unsatisfactory. Contrary to what it states, widespread causal overdetermination in type-involving cases is not a logical consequence of the principle of proportionality and the assumption that types exist. To see this, suppose that this principle is true and that there are types. In this case, that types are causally efficacious does not have to be true. The principle of proportionality, by itself, is neutral with regard to the question about the causal efficacy of types. Likewise, the thesis that there are types does not, by itself, entail that types are, or are not, causally efficacious. If the principle of proportionality and the foregoing thesis are taken together, the result is the same: We are not logically committed to the causal efficacy of types, as it is possible to imagine a possible world where the principle of proportionality is true, but types are just not the kind of thing that can, in

bizarre, and prima facie false, view — that various imaginary objects actually exist.

${ }^{34}$ A substantiation of the principle of parsimony is beyond the scope of this essay. For possible arguments in favor of this principle, see, e. g., Baker 2016 and Sober 2015. 
principle, play the role of the cause.

Another potential way to justify widespread causal overdetermination in type-involving cases is to argue that if we reject such overdetermination, then although epistemic and ontological complexity with regard to causation will decrease, such complexity will increase in some other respect, and so the resultant alternative will not be more parsimonious than (and, hence, preferable to) a theory that presupposes widespread causal overdetermination in type-involving cases. Is this kind of argument successful? There is no doubt that rejecting widespread causal overdetermination, by itself, decreases epistemic/ontological complexity. So a possible increase in epistemic/ontological complexity in the case of rejecting widespread causal overdetermination can only be caused by rejecting what commits us to such overdetermination-namely, the Proportionality Argument. In fact, however, rejecting this argument does not give rise to the mentioned increase. Will epistemic/ontological complexity increase if we abandon the principle of proportionality? Such an increase is far from obvious, as there are accounts of causation that (a) do not seem to contribute to an increase in complexity but (b) make it possible to avoid the commitment to the existence of causally efficacious types and, hence, widespread causal overdetermination in type-involving cases. ${ }^{35}$ For the sake of argument, however, let us assume that the foregoing question is to be answered in the affirmative. We can also grant that epistemic/ontological complexity will increase if we completely exclude types from our ontology. But even in this case, we can reject the Proportionality Argument without an increase in epistemic/ontological complexity - by arguing that there is no need to postulate that types are the kind of thing that can stand in causal relations.

A proponent of the Proportionality Argument could object that if we argue this way, then epistemic complexity, in fact, increasesbecause now, a considerable part of our prima facie true discourse presupposing the causal efficacy of types is false and, hence, needs

35 Thus, according to the account of causation put forward by Jackson and Pettit (1990), types play a particular explanatory role, while being essentially causally inefficacious (specifically, types play this role by virtue of being "causally relevant" with regard to the existence of the corresponding tokens - the only entities having causal power). 
to be paraphrased away; yet it is often unclear how this can be done. Take, for instance, sentences like "Conan Doyle wrote The Hound of the Baskervilles" and "Beethoven composed Symphony No. 5." As Walters (2013) points out, such sentences cannot be adequately replaced with sentences that do not commit us to the causal efficacy of types.

There are at least two plausible ways to respond to this objection. First, it can be argued, pace Walters (2013), that it is far from obvious that sentences of the kind mentioned above cannot, in fact, be paraphrased away. A potential way to do this is as follows: "Conan Doyle was the first to write a text-token of The Hound of the Baskervilles," "Beethoven was the first to compose a text-token of the score of Symphony No. 5," etc. ${ }^{36}$ Second, one could (a) grant that the epistemic complexity in the case of rejecting the causal efficacy of types actually increases because of the need to paraphrase away certain sentences but (b) argue that the overall complexity in this case is nevertheless much lower than the overall complexity in the case of postulating that types are causally efficacious, as in the latter case, we must deal with a lot more problems, including not only the problem of widespread causal overdetermination but also a number of problems related to the nature of abstracta (for example, we must provide a satisfactory explanation of how it is possible for an abstract - and, hence, nonspatiotemporal - entity to causally interact with other entities, including spatiotemporal ones).

A proponent of the Proportionality Argument could also try to justify widespread causal overdetermination in type-involving cases by arguing that there is some theoretically established relation metaphysically responsible for this overdetermination. But what could this relation be? It is widely held that tokens instantiate types. However, instantiation cannot play the role of a relation that gives rise to causal overdetermination in type-involving cases, since instantiation, as it is standardly understood, is essentially acausal: While tokens instantiate types, they do not transfer causal power to types;

${ }^{36}$ Alternatively, following Brock (2002), one could paraphrase sentences of the kind being discussed by prefixing them with "according to the hypothesis about the causal efficacy of types": "According to the hypothesis about the causal efficacy of types, Conan Doyle wrote The Hound of the Baskervilles," "According to the hypothesis about the causal efficacy of types, Beethoven composed Symphony No. 5," etc. 
nor do types transfer such power to tokens. Alternatively, it could be suggested that the relation being discussed could be derivative causation, the relation that was first introduced by Dodd (2007). According to him, this relation holds between types and their tokens, as a result of which the former derive causal power from the latter. Thus, whenever a text-token of $A P$ causes something (say, buying copies of all of Easton Ellis's other works), it can be said — due to fact that the corresponding type derives causal power from this token - that this type causes the same. The given suggestion, however, is problematic. Unlike instantiation, derivative causation is a novel relation, one that can hardly be characterized as theoretically established. In light of this, this relation itself requires justification. In particular, the following question must be answered: Why think that types derive causal power from their tokens, especially in light of the fact that it is widely believed that types, being abstracta, are acausal? There is no satisfactory answer to this question, ${ }^{37}$ and the prospects of finding such an answer look bleak. ${ }^{38}$

${ }^{37}$ For a powerful critique of the answer given by Dodd (2007), see Davies 2009 and Juvshik 2018.

${ }^{38}$ As Davies (2009) points out, the problem of justifying derivative causation can be avoided if such causation is understood in the sense similar to that of "analogical predication" - the notion that dates back to Aquinas (2014) and, in contemporary aesthetics, is used, most notably, by Wolterstorff $(1975,1980)$. Analogical predication amounts to predication that makes it possible to ascribe different, though "analogical," properties using the same predicate. To illustrate, consider the predicate "is roughly fifteen minutes long" contained in the sentences "The Moonlight Sonata is roughly fifteen minutes long" and "A correct performance of the Moonlight Sonata is roughly fifteen minutes long." In the latter sentence, this predicate is used literally - to refer to the property being roughly fifteen minutes long. In the former sentence, however, the use of the predicate cannot be literal, for the Moonlight Sonata is an abstractum and, hence, cannot have a duration. This use can be analogical, however: It can pick out an analogue of the literal property - say, the property being such that its correct performances are approximately eight minutes long. If derivative causation is understood in the analogical sense, then the justification problem does not arise, as in this case, types do not literally derive causal power from their tokens. It should be stressed, however, that given our purposes, we cannot understand derivative causation in the analogical sense. If we understand it this way, we must acknowledge that types derive their causal power from the corresponding tokens only analogically — and, hence, that they are not really causally efficacious; rather, they are causes solely in some nonliteral, 
Also, following Jackson and Pettit (1990), one could suggest that the relation under consideration be treated as programming. The nature of programming can be illustrated with the following example. ${ }^{39}$ Suppose there are a square peg and a round hole whose diameter is equal to the side of the square. Clearly, the peg cannot be fitted into the hole - but how exactly can this be explained? According to Jackson and Pettit (1990), this question can be answered by saying that the squareness of the peg programs the presence of the impenetrable part of the peg - by ensuring, "as a matter of elementary geometry, that there will be an impenetrable part of the square end to obstruct its passage through the hole and again it may be this part or that which provides the obstruction" (Jackson and Pettit 1990: 115). Thus, programming is, roughly, the relation by virtue of which an abstractum (say, a property) can, at least in part, determine - and, hence, be causally relevant for-a particular concrete causal fact. In light of this, it can be said that at least some types (e.g., the type $A P$ ) can stand in the relation of programming to certain concreta (e.g., tokens of $A P$ ) and, ipso facto, be capable of being causally relevant for various concrete causal facts (e.g., the fact that John bought copies of all of Easton Ellis's other works).

Is the foregoing suggestion satisfactory? The first thing to note is that the relation of programming can hardly be called theoretically established, and so, like the previous suggestion, this one faces the problem of justifying the introduction of this relation into our ontology. Furthermore, according to Jackson and Pettit (1990), while programming is responsible for causal relevance, it cannot be used to account for causal efficacy. On the contrary, the key idea behind their proposal is to provide a causally exclusive explanation (a "program" explanation, as they term it) - an explanation that makes it possible to take into account the explanatory role of abstracta without adopting the view that the latter can stand in causal relations. As a result, if

metaphorical sense. This result, however, fails to solve the initial problem - that of explaining widespread causal overdetermination in type-involving casessince this problem is concerned with real causation and, hence, to solve it, it is not sufficient to postulate that types derive causal power from their tokens in the analogical sense.

${ }^{39}$ See Jackson and Pettit 1990: 115. 
a proponent of the Proportionality Argument follows the suggestion being discussed, s/he will not be able to attain her/his goal- - that of accounting for the existence of widespread causal overdetermination of the kind discussed above.

Thus, neither instantiation, nor derivative causation, nor programming can play the role of the theoretically established relation metaphysically responsible for widespread causal overdetermination in type-involving cases. At the same time, there seem to be no other potentially plausible candidates that can play this role. So an attempt to justify widespread causal overdetermination in type-involving cases by appealing to some theoretically established relation that could be metaphysically responsible for this overdetermination does not seem promising.

\section{Conclusion}

According to the Proportionality Argument, if we accept the principle of proportionality and a number of plausible assumptions, we can demonstrate that at least some types can stand in causal relations. This argument, however, commits us to the existence of widespread causal overdetermination in type-involving cases, and this commitment is epistemically and ontologically burdensome. It is epistemically burdensome because it requires us to provide a plausible explanation of what widespread causal overdetermination is, how exactly it occurs, etc. The ontological burden amounts to the requirement that we posit a new kind of entity, in particular the presence of a multitude of two or more causes of the same effect that are simultaneously sufficient. Thus, adopting the Proportionality Argument comes at a serious epistemic and ontological cost. Yet, as has been shown, this cost does not seem justified. So, assuming the principle of parsimony is true, it is more reasonable to adopt a more epistemically and ontologically parsimonious view - a view that does not involve the Proportionality Argument.

Alexey Aliyev School of Philosophy and Cultural Studies, HSE University 21/4 Staraya Basmannaya Ulitsa, Building 1 105066, Moscow, Russia 


\section{References}

Aliyev, Alexey. 2019. What is an instance of an artwork. Estetika 26: 163-85. Alward, Peter. 2004. The spoken work. Journal of Aesthetics and Art Criticism 62: $331-7$.

Aquinas, Thomas. 1485. The Summa Theologica. New York: Catholic Way Publishing, 2014.

Baker, Alan. 2016. Simplicity. In The Stanford Encyclopedia of Philosophy. Edited by Edward N. Zalta. URL = <https://plato.stanford.edu/archives/win2016/ entries/simplicity/>

Brock, Stuart. 2002. Fictionalism about fictional characters. Noûs 36: 1-21.

Collingwood, R. G. 1958. The Principles of Art. New York: Oxford University Press.

Currie, Gregory. 1989. An Ontology of Art. New York: St. Martin's Press.

Davies, David. 2009. Dodd on the 'audibility' of musical works. British Journal of Aesthetics 49: 99-108.

Davies, David. 2010. Multiple instances and multiple 'instances.' British Journal of Aesthetics 50: 411-26.

Davies, David. 2015. Varying impressions. The Journal of Aesthetics and Art Criticism 73: 81-92.

Deutsch, Harry. 1991. The creation problem. Topoi 10: 209-25.

Dodd, Julian. 2000. Musical works as eternal types. British Journal of Aesthetics 40: 424-40.

Dodd, Julian. 2007. Works of Music: An Essay in Ontology. Oxford: Oxford University Press.

Howell, Robert. 1979. Fictional objects: how they are and how they aren't. Poetics 8: 129-77.

Jackson, Frank \& Pettit, Philip. 1990. Program explanation: a general perspective. Analysis 50: 99-108.

Juvshik, Tim. 2018. Abstract objects, causal efficacy, and causal exclusion. Erkenntnis 83: 805-27.

Kivy, Peter. 1983. Platonism in music. Grazer Philosophische Studien 19: 109-29.

Levinson, Jerrold. 1980. What a musical work is. Journal of Philosophy 77: 5-28.

Mag Uidhir, Christy. 2013. Art \& Art-Attempts. Oxford: Oxford University Press.

Predelli, Stefano. 2001. Musical ontology and the argument from creation. British Journal of Aesthetics 41: 279-92.

Sartre, Jean-Paul. 2004. The Imaginary: A Phenomenological Psychology of the Imagination. Routledge.

Sider, Ted. 2003. What's so bad about overdetermination? Philosophy and Phenomenological Research 67: 719-26.

Sober, Elliott. 2015. Ockham's Razor: A User's Manual. Cambridge: Cambridge University Press.

Van Inwagen, Peter. 1977. Creatures of fiction. American Philosophical Quarterly 14: 299-308. 
Walters, Lee. 2013. Repeatable artworks as created types. British Journal of Aesthetics 53 (4): 461-77.

Wetzel, Linda. 2008. Types and Tokens: An Essay on Universals. Cambridge, MA: MIT Press.

Wolterstorff, Nicholas. 1975. Toward an ontology of art works. Noûs 9: 115-42. Wolterstorff, Nicholas. 1980. Works and Worlds of Art. Oxford: Clarendon Press. Yablo, Stephen. 1992. Mental causation. The Philosophical Review 101: 245-80. Yablo, Stephen. 1997. Wide causation. Philosophical Perspectives 11: 251-81. 